\title{
Practice and Exploration of Innovative and Entrepreneurial Talent Cultivation in Jinan University against the Background of "Entrepreneurship and Innovation"
}

\author{
Yudong Zeng \\ Jinan University \\ Guangzhou, Guangdong, 510632
}

\begin{abstract}
Faced with the national strategic layout of "entrepreneurship and innovation", colleges and universities shoulder the important task of cultivating innovative and entrepreneurial talents. As a century-old overseas Chinese university, in terms of innovative and entrepreneurial talent cultivation, Jinan University combines the characteristics of running a school, gives full play to its own advantages, and continuously carries out practice and exploration through a series of effective reform measures, and has formed a unique mode of innovative and entrepreneurial talent cultivation, achieving remarkable results, providing useful reference for improving the cultivation mode of innovative and entrepreneurial talents in colleges and universities.
\end{abstract}

Keywords-Jinan University; innovation and entrepreneurship; talent cultivation

\section{INTRODUCTION}

In recent years, the state has proposed the social development idea of innovation and entrepreneurship, and the "entrepreneurship and innovation" with "mass entrepreneurship and innovation" as the core has become the trend of the times. General Secretary Jinping XI pointed out: "innovation sustains the progress of the society, and entrepreneurship is an important way to promote economic and social development and improve people's livelihood." [1] Thus, China's innovation and entrepreneurship education has been raised to a new height. At present, college students are the main body of innovation and entrepreneurship education reform, and innovation and entrepreneurship education plays an important role in the cultivation of talents in colleges and universities. Implementing innovation and entrepreneurship education, cultivating innovation and entrepreneurship, and improving innovation and entrepreneurship capabilities are important measures to promote the comprehensive reform of higher education, are urgent needs to implement the innovation-driven development strategies for the country, to promote economic development, and to cultivate talents, and are the historical missions entrusted to colleges and universities in the era of mass entrepreneurship and innovation.

\section{THE SPECIFIC PRACTICE AND EXPLORATION OF} INNOVATIVE AND ENTREPRENEURIAL TALENT CULTIVATION IN JINAN UNIVERSITY

As an important measure for the transformation and development of contemporary Chinese colleges and universities, strengthening the innovation and entrepreneurship education is an inevitable choice for Chinese colleges and universities to break through the traditional knowledge education mode and move toward excellence [3]. In recent years, Jinan University has positively responded to the call of "mass entrepreneurship and innovation" of the party and the state, given full play to the advantages of comprehensive university and international source of students, comprehensively launched the reform of innovative and entrepreneurial talent cultivation mode, built innovative and entrepreneurial talent cultivation system with distinctive characteristics, and has made positive exploration and practice in aspects such as deepening the reform of innovation and entrepreneurship education.

\section{A. Focus on innovation, and launch the twin-engine innovative and entrepreneurial talent cultivation system}

(1) In the aspect of institutional innovation, the university takes the innovation and entrepreneurship education as the core work of its talent cultivation, and includes it in the Jinan University High-level Construction and Comprehensive Reform Plan (2015-2020) and the 28 Articles of Jinan University High-level University Construction Reform and the 13th Five-Year Development Plan of Jinan University, formulates the Implementation Plan of Jinan University's Deepening of Innovation and Entrepreneurship Education Reform, and systematically promotes the comprehensive deepening of innovation and entrepreneurship education reform. At present, the university has explored and formed a teaching mechanism reform systemic project of "three-threethree undergraduate teaching management system", with the core of the development of teachers' teaching and the development of students' learning. Through vigorously managing the three core elements of undergraduate teaching of teachers, curriculum, and students, building the three 
platforms of undergraduate teaching core team, undergraduate curriculum construction and management center, and the "outstanding future" innovative talent education plan, and implementing the three sets of systems of teaching style and learning style grading forecasting and disposal system, teachers' teaching performance evaluation system, and classroom teaching assistance system, the transformation from "undergraduate teaching management" to "undergraduate teaching governance" has been realized.

(2) In the aspect of talent cultivation mode innovation, the university takes advantage of the integration of production and education, creates space for mass entrepreneurship and innovation, cultivates soil of free exploration and innovation, and roots innovation elements in curriculum, projects and platforms to build the 'outstanding future' innovative and entrepreneurial talent cultivation system. Guided by the "widespread and general" education concept, taking the five links of "talent cultivation plan - the first class education - the second class education - innovation and entrepreneurship training - innovation and entrepreneurship incubation" as the center of effort, from the shallower to the deeper, through progressing gradually, it takes innovation spirit, entrepreneurship awareness and innovation and entrepreneurship capabilities as important criteria for evaluating the talent cultivation quality, and integrates innovation and entrepreneurship education into the whole process of talent cultivation; optimizes the autonomy of postgraduate degree programs, supports degree programs to independently create innovation and entrepreneurship platforms, deepen international exchanges and cooperation, carry out master-doctor through cultivation, and unites a group of teaching core strength through a series of reforms, and cultivates a group of innovative talents.

\section{B. Integrate comprehensively, and construct the multi- dimensional innovative and entrepreneurial talent cultivation curriculum system}

(1) Comprehensively integrate the innovation and entrepreneurship elements into the curriculum teaching reform. As early as 2008, the university had officially implemented the flexible standard academic credit system consisting of "complete elective system" plus "standard academic credit system" plus "elastic floating system" to fully encourage the personality development of students. In 2015, it revised and improved the accumulation and transfer system of innovation and entrepreneurship academic credits. Through the flexible floating of academic credits, it realized the flexible educational system to provide students with relaxed conditions for adjusting their academic progress, retaining their academic status and innovation and entrepreneurship. It actively promotes the reform of teaching methods to provide teaching support for innovation and entrepreneurship education. $90 \%$ of the classrooms in the university use the computer aided system (CAS) to provide hardware support for the extensive implementation of inspired interactive teaching in the classroom; it encourages small-class teaching with the classroom of less than 30 students of 2,771 in the 2015-2016 school year. It deepens the examination reform and advocates the implementation of non-standard answer exams. In the first semester of the 2016-2017 school year, 289 curriculums applied for non-closed exams, and over 100 curriculums applied for curriculum examination reform trial.

(2) Comprehensively integrate the innovation and entrepreneurship elements in the general education curriculum. In 2011, the university issued the Several Decisions on Implementing the "Outstanding Future" Innovative Talent Education Plan, which clearly requires the integration of innovation elements in the construction of general education, professional basic education, and professional education curriculums. For example, the university offers a wide range of research methods, academic frontier, and interdisciplinary general education courses, such as Nobel Prize Analysis, Critical Thinking, Introduction to Literature, History and Philosophy, and Introduction to Natural Science, to further broaden students' academic visions and horizons.

(3) Comprehensively integrate innovation and entrepreneurship elements into the innovation and entrepreneurship platform curriculums. In 2014, the university revised the undergraduate talent cultivation program, and set up compulsory innovation and entrepreneurship curriculum modules of 6 academic credits for all students, and independently built two batches of online open courses, totaling 70, among which, the Knowledge Entrepreneurship and Action -- the Foundation of College Students Entrepreneurship is listed as a national boutique video open class. The university has also offered more than 20 courses on innovation and entrepreneurship such as College Students' Innovation and Creativity, Entrepreneurship Philosophy and National Conditions Analysis and Business Design, and compiled and published innovation and entrepreneurship education materials of Introduction to Entrepreneurship, and built the case library of Evaluation and Analysis of New Business Models 1-3 Series and Entrepreneurial Management Network Case Platform, which increase the proportion of practical teaching, and strengthen the cultivation of students' knowledge application, practical innovation and professional competence by setting up innovative entrepreneurship courses.

(4) Comprehensively integrate innovation and entrepreneurship elements in the professional education curriculum of the "profession + innovation and entrepreneurship" type. The university organically combines innovation and entrepreneurship education with discipline professional education. All kinds of professional courses are closely combined with innovation and entrepreneurship education to enrich the resources of innovation and entrepreneurship education in professional curriculums, and innovation and entrepreneurship education is integrated into each link of knowledge teaching, course discussion and course assessment. For example, in 2014, the university offered a double-degree program in business administration (entrepreneurship management direction). In 2016, it offered the Optoelectronic Information Science and Engineering Innovation Class and the Engineering Mechanics "Weichang QIAN Innovation Class". Through the implementation of small-class group teaching, tutor responsibility system, and international teaching, it cultivates innovative talents to meet the industrial needs of Guangdong Province. 


\section{Integrate resources, and launch multi-level innovation and entrepreneurship practice and incubation platform}

(1) Build the brand that "wins through innovation", and promote the vigorous development of innovation entrepreneurship practice. The university takes the lead in domestic colleges and universities to set up undergraduate innovation competition that "wins through innovation" in the "quarterly competition + stage competition" mode. The brand activity is a comprehensive innovation series with the theme of exploring innovative talents, discovering innovative achievements, and building innovative platforms. At present, 8 seasons with 36 games have been held, and 280 teams have participated in it, with more than 10,000 people have directly involved in it, becoming the brand for the cultivation of innovative talents in the university and the "dream factory" in the minds of Jinan University students, arousing enthusiastic response both on campus and off campus.

(2) Implement an open cooperation strategy, and build diversified talent incubation projects and platforms. Based on the background of international source of students, the university actively integrates resources, attracts off-campus resources such as government, enterprises, and alumni, and builds multi-level and diversified innovation and entrepreneurship practice and incubation platforms. For example, in March 2015, when the two sessions of the National People's Congress paid close attention to "mass entrepreneurship and innovation", the university timely joined hands with listed companies to jointly build the first platformbased entrepreneurial base project of "WE Innovation Space" in China, and build the mass innovation and entrepreneurship platform for college students to provide the "0 threshold", "large capacity" and "open" workspace, cyberspace, social space and resource sharing space for students who are interested in innovation and entrepreneurship, to help innovation results achieve the market-oriented transformation. In order to explore the talented and individualized cultivation mode, and promote the emergence of top-notch innovative and entrepreneurial talents, the university has organized and implemented the "outstanding future" innovative talent incubation project, and established 12 incubation bases such as "future scientists", "future media leaders", and "future legal elites" to carry out the talent cultivation mode innovation and the collaborative education practice.

(3) Combine with the practice of disciplines, and improve the practical teaching system. In recent years, combined with the practice of disciplines, the university has established 10 national college students' off-campus practice bases, and 24 provincial practice bases. For example, the establishment of WE Innovation, Hong Kong, Macao and Taiwan Overseas Chinese Youth Mass Innovation and Entrepreneurship Space, Youth Innovation Space, Graduate Innovation Park, College Student Work-study Practice Base, JNU Innovation Dream Factory, Hong Kong, Macao and Taiwan Overseas Students Innovation and Entrepreneurship Practice Training Platform, Seaweed Life Hall, Yanhan Intelligent Made, and other innovation and entrepreneurship practice platforms that cover all campuses, and the establishment of a group of off-campus innovation and entrepreneurship practice education bases relying on platforms such as Guangzhou Zengcheng "Qiaomengyuan" Hong Kong, Macao and Taiwan Overseas Chinese Students Innovation and Entrepreneurship Incubation Base, Guangdong Wushan Science and Technology Park, Guangdong Guanhao Science and Technology Park and Nansha Free Trade Zone. Numerous bases collaboratively operate with the three sections of "wins through innovation" competition, entrepreneurship training camp and innovation and entrepreneurship incubation base of the university to achieve the combination of reality and virtual space, displaying the energy of "entrepreneurship and innovation" to the maximum.

\section{Make systematic plans, and improve the safeguard mechanism that fully covers the innovation and entrepreneurship}

(1) Pay high attention to the improvement of leadership system and working mechanism. The university resolutely implements the "partner" project and establishes an innovation and entrepreneurship education leading team with the president as the team leader, the responsible vice president as the deputy team leader, and responsible people of relevant departments such as the Office of Teaching Affairs, the School of Entrepreneurship Education, the Graduate School, the Student Affairs Office, the Student Employment Guidance Center, the CCYL Committee, the HR Development and Management Office and the Finance and State Asset Management Office as the members, to organize and coordinate the innovation and entrepreneurship work of the university in a unified way, form the linkage and coordination mechanism of innovation and entrepreneurship work under the joint management of all departments, and make overall planning and effectively promote the development of the innovation and entrepreneurship work of the university. In addition, the university has established the university-level innovation and entrepreneurship guidance service work organization - Innovation and Entrepreneurship Education Center of Jinan University, and the responsible vice president is fully responsible for the innovation and entrepreneurship education. And it has established the innovation and entrepreneurship work regular meeting system to regularly hold innovation and entrepreneurship regular meetings to research and deploy innovation and entrepreneurship work.

(2) Promote the development through systemic advancement, scientific planning and reform and innovation. Under the background of "entrepreneurship and innovation", the university insists on its unique advantages of running a university, serves the national "Belt and Road" Initiative and the construction of Guangdong-Hong Kong-Macao Greater Bay Area, insists on entrepreneurship led by innovation and employment driven by entrepreneurship, activates the advantages of university technology, talents and resources, and promotes the transfer and transformation of scientific and technological achievements, and actively adapt to and lead the new normal of economic development. For example, the university implements the "Jinan Talents Introduction Program" and "Jinan Elite Faculty Program", and strives to build the "green channel for high-level talents introduction" to form a high-level talent cluster effect, effectively opening up the connection point between colleges and universities and 
economic innovative development, and supporting the "entrepreneurship and innovation" talent cultivation.

(3) Strengthen the guidance, and improve the construction of assessment and incentive systems. According to the Jinan University High-level Construction and Comprehensive Reform Plan (2015-2020), the university clarified the promotion of the transformation mechanism of achievements and the reform of the industry-universityresearch cooperation mode, and the establishment of the direct investment of strategic venture capital fund to the major scientific research achievements of the university to ensure that teachers focus on original innovation. For those who make important contributions to the transformation of scientific and technological achievements, no less than $85 \%$ of the net income from the transfer or licensing net income of such scientific and technological achievements shall be taken as awards and remunerations, and most of the transfer income shall be owned by the project team; include the innovation and entrepreneurship education performance in the important assessment indicators of teachers' professional and technical job evaluation, post employment and performance assessment; Under the "Undergraduate Education President Awards", the category of "Practice and Innovation Education" is specially designed to exclusively recognize teachers who have outstanding achievements in innovation and entrepreneurship education. complete a series of systems such as the Management Measures for the "College Students Innovation and Entrepreneurship Training Program" of Jinan University, the Measures for the Assessment of Undergraduate Students Innovation in Jinan University, and the Management Measures for Graduates' Innovation and Entrepreneurship Education Projects in Jinan University to establish the system for giving bonus points for comprehensive assessment of innovation and entrepreneurship achievements and exemption from admission exams for "scientific research and innovation category". For example, in 2011, the university set up a "scientific research and innovation category (B)" special exemption from admission exams system to give the highest $30 \%$ indicators of exam-free candidates to those who have made outstanding achievements in innovation and entrepreneurship.

(4) Strengthen guarantee, and set up special funds to ensure capital investment. The university sets up special funds for innovation and entrepreneurship to ensure the smooth implementation of innovation and entrepreneurship, and uses the basic scientific research funds of the central universities in accordance with regulations to support the students to carry out innovative research work; and allocates special funds from the high-level university construction funds for the construction of an innovation and entrepreneurship education system; optimizes the structure of capital expenditure, increase capital investment in aspects such as talent cultivation standard reform and innovation and entrepreneurship teaching resources, innovation and entrepreneurship practice platform on campus and off campus, and faculty construction; and attracts university managers, alumni and corporate social funds to support and encourage students' innovation and entrepreneurship. It establishes special scholarship for innovative talents, and awards 300,000 yuan a year to 30 students who have made outstanding achievements in innovation and entrepreneurship; sets up academic science and technology competition awards to award students who have won in various scientific and technological academic competitions at various levels; sets up the "Internet +" innovation and entrepreneurship competition awards to award the winning teams with 15,000-400,000 yuan to encourage students to carry out scientific research and innovation training.

(5) Implement training, and strengthen the faculty construction. At present, the innovation and entrepreneurship faculty structure of the university is reasonable. With the dean of the School of Entrepreneurship Education as the leader, a group of full-time innovation and entrepreneurship faculty with reasonable age structure and rich theoretical and practical experience has been built. And academicians and excellent talents from various industries are invited to directly participate in the innovation and entrepreneurship guidance, and entrepreneurs, successful entrepreneurs, and venture capitalists are invited to directly work as the entrepreneurial mentors; Relying on the "wins through innovation" competition and the School of Entrepreneurship Education, the "innovation guidance mentors" including on campus and off campus teachers and expert judges have reached over 100 people. In addition, the university has carried out all-round innovation and entrepreneurship education and training. Relying on the "undergraduate teaching core team", the Teacher Teaching Development Center, the Innovation Education Promotion Association, the "wins through innovation" project development promotion team, and the college students' innovation achievements display skills guiding team, it has held 122 special exchange activities including "taste teaching", and it regularly organizes key teachers to go to the United States, Hong Kong, Taiwan and other regions to carry out innovation and entrepreneurship education and training to improve the teaching level of innovation and entrepreneurship education teachers.

\section{ACHIEVEMENTS AND TYPICAL RESULTS OF THE} INNOVATIVE AND ENTREPRENEURIAL TALENT CULTIVATION IN JINAN UNIVERSITY

The Fifth Plenary Session of the 18th CPC Central Committee clearly placed innovation at the top of the five development concepts during the 13th Five-Year Plan period, emphasizing that innovation should be placed at the core of the country's overall development, and that innovation should run through all the work of the party and the state. Deepening the reform of innovation and entrepreneurship education, accelerating the development of innovation-driven development, and promoting the improvement of the quality of national innovation are the responsibilities of the times for colleges and universities to carry out the basic state policy of mass entrepreneurship and innovation. [4] With the in-depth implementation of the innovative and entrepreneurial talent cultivation, taking the "entrepreneurship and innovation" as the carrier, Jinan University integrates the high-quality teaching resources on campus and off campus, and promotes the integration of science and education, and the overall improvement of the industry-university-research coordinated education and teaching quality with large coverage, many 
beneficiaries and obvious achievements, winning wide praise from the society.

\section{A. Win numerous awards in competitions, with rich scientific research achievements}

The first is in the aspect of innovation and entrepreneurship competitions. The university has a strong atmosphere of innovation and entrepreneurship. Its students have made great achievements in various domestic and foreign competitions such as "Challenge Cup", and China College Students' Innovation and Entrepreneurship Competition, and its talent cultivation quality has been gradually improved. For example, from 2013 to 2016, the university students won awards such as "Most Creative Projects", "My Favorite Projects", "Excellent Papers" and "Best Entrepreneurship Projects" at the China College Students' Innovation and Entrepreneurship Annual Conference for four consecutive years, ranking among the top universities in the country in terms of the number of awards; the university won the champion of "2015 Enactus China Exposition", and participated in the global finals representing China and won the third prize in the finals; through the brand of "wins through innovation", the university has led the vigorous development of innovation and entrepreneurship practice such as "College Students' Innovation and Entrepreneurship Project", "Challenge Cup", "College Students' Entrepreneurship Competition" and "Internet Plus". So far, the university has won 19 gold medals, 26 silver medals and 29 copper medals in the national and provincial innovation and entrepreneurship competitions such as "Internet Plus", "Challenge Cup" and "College Students' Entrepreneurship Competition". The second is in the aspect of scientific research achievements. Since 2015, 5 national college students' off-campus practice education bases, 3 national talent cultivation mode innovation experimental areas, and 10 provincial college students' off-campus practice education bases of the university have been approved. Undergraduates have published more than 300 academic papers, including more than 80 academic papers in category A (SCI/EI/ISSHP, etc.), among which there are some excellent papers with impact factors exceeding 7; the students have applied for more than 30 invention patents, with over 10 being authorized, and won more than 100 provincial and ministerial scientific and technological academic competition awards. From 2011 to 2015, nearly 1,700 Challenge Cup projects were approved won the bids), involving more than 8,000 students and the funding of more than 4 million yuan. From 2015 to 2016 , there were a total of 1,490 "College Students' Innovation and Entrepreneurship Projects", with the funding of 7.3 million yuan. Students were very active in all kinds of innovation and entrepreneurship practices, and the number of applications for all kinds of projects at all levels and the number of participants were on the rise.

\section{B. The reform features are distinctive, and the demonstration effect is obvious}

By virtue of the pioneering test of innovation and entrepreneurship work reform, the innovation and entrepreneurship work of the university has distinctive features, with obvious demonstration and leading role. In 2016 the university was selected as the "College Students' Innovation and Entrepreneurship Education Demonstration University in Guangdong Province" by the Department of Education of Guangdong Province. At the same time, it was selected as the "National First Demonstration Universities that Deepen the Innovation and Entrepreneurship Education" by the Ministry of Education of the People's Republic of China. Being successively selected as the provincial and national demonstration university is a high affirmation for the university's deepening of the innovation and entrepreneurship education reform. In recent years, the school has implemented the "three-three-three undergraduate teaching management system", the 'outstanding future' innovative and entrepreneurial talent cultivation system, which is driven by the dual-engineering innovation and entrepreneurship education system project, established the innovation competition that "wins through innovation", the "outstanding future" innovative talent incubation project, "WE Innovation Space", and the WE Innovation, Hong Kong, Macao and Taiwan Overseas Chinese Youth Mass Innovation and Entrepreneurship Space. Through the student-centered innovative and entrepreneurial talent cultivation mode, the students' main role has been given full play, and their scientific thinking, innovative consciousness and team spirit have been cultivated, and the comprehensive ability of students to use the knowledge they have learned to solve problems has been enlightened and cultivated. Many colleges and universities across the country have come to our university for investigation and believed that the mode has good reference value. In addition, through various methods such as theoretical discussion, practical project application and implementation of pilot projects, the university has continuously accumulated practical experience and established advanced models, thus forming an atmosphere of campus innovation and entrepreneurship education, further giving full play to its demonstration and leading role, comprehensively promoting the university's innovation and entrepreneurship education and the improvement of innovative and entrepreneurial talent cultivation quality.

\section{The education effect is obvious, and the media pays close attention to it}

The university gives full play to the fine traditions of innovation and entrepreneurship and the characteristics of running a university. It runs innovation and entrepreneurship education through the talent cultivation system, carries out a variety of innovation and entrepreneurship brand activities, and creates a strong atmosphere of innovation and entrepreneurship. At present, the university has organized and incubated 23 undergraduate entrepreneurial projects, and it has nearly 10 registered companies, and the operation income of several entrepreneurial projects exceeds 1 million. Besides, the innovative and entrepreneurial talent cultivation effect of the university has been widely concerned by the social media and 
gained a good reputation. For example, the People's Daily reported on the reform of innovation and entrepreneurship education of the university by two-thirds of the layout. Xinhua News Agency reported on the innovation and entrepreneurship platform of Hong Kong, Macao and Taiwan overseas Chinese students in the form of news release. Media at home and abroad such as China Youth Daily, Nanfang Daily, Macao Daily News, Guangdong News, and Hong Kong Wen Hui Bao, and Ta Kung Pao reported on the innovation and entrepreneurship education reform measures of the university for hundreds of times, and publicized its innovation and entrepreneurship work initiatives and achievements to all walks of life.

\section{CONCLUSION}

The innovative and entrepreneurial talent cultivation has become the theme of the development of higher education in China. As the main front for the cultivation of innovative and entrepreneurial talents, colleges and universities should accurately grasp the current development trend of the times and the strategic deployment of national innovation and entrepreneurship, and indispensably raise the banner of innovation and entrepreneurship and continue to deepen the innovation and entrepreneurship education reform. In the future, Jinan University will further adapt to the requirements of the state on the innovative and entrepreneurial talent cultivation under the background of "entrepreneurship and innovation", actively carry out research and practice on the cultivation of innovative and entrepreneurial talents, cultivate students' innovation and entrepreneurship spirit, stimulate their awareness of innovation and entrepreneurship, and explore their innovation and entrepreneurship capabilities, and construct an innovative and entrepreneurial talent cultivation system with school-running characteristics, to give play to its demonstration and leading role in domestic innovation and entrepreneurship education in colleges and universities, and provide powerful talent support and strong guarantee for the promotion of the realization of the goal of support for the realization of the goal of strengthening moral education and cultivating people, and the serving of the requirements of national innovation-driven strategy.

\section{ACKNOWLEDGMENT}

Fund project: This paper is the research achievement of 2018 Guangdong Province Philosophy and Social Science Planning Discipline Joint Project of Research on Innovation and Entrepreneurship Education in Guangdong colleges and Universities under the Background of Guangdong-Hong Kong-Macao Greater Bay Area (GD18XMK09), and 2017 Guangzhou Association of Social Science Societies' "Guangzhou Young Scholars" project of Research on Innovation and Entrepreneurship Education Practice of Colleges and Universities in Guangzhou (17QNXR40).

Introduction to the author: Yudong ZENG, Party \& Government Affairs Office of Jinan University, research assistant, Master of Law. (Guangzhou/510632)
Contact address: Party \& Government Affairs Office of Jinan University, No. 601 West Huangpu Road, Guangzhou, Guangdong.

\section{REFERENCE}

[1] Jinping XI sent a congratulatory letter to the opening of the Global Entrepreneurship Week China: innovation sustains the progress of the society [N] People's Daily Overseas Edition, November 9, 2013 (1).

[2] Xi CHEN. Make Innovation and Entrepreneurship Education Run Through the Whole Process of Talent Cultivation in Colleges and Universities [J]. China Higher Education, 2010 (12): 4-6

[3] Yingjie HUANG. The Philosophical Thinking of the Innovation and Enterprise Education in Chinese Universities [J]. Journal of higher Education Management, 2016 (1): 74-79.

[4] Wenbing GAO. Innovation and Entrepreneurship Education in Chinese Colleges and Universities under the Background of Mass Entrepreneurship and Innovation [J]. China Higher Education Research, 2016 (1): 50. 